\title{
1 Beers and Blurred Boundaries: The Spatial and Gendered 2 Organisation of Pre-Match Venues for English Football Fans
}

3

4

5

6

\begin{abstract}
Academic research into sports fans has grown in recent years with studies examining a variety of aspects associated with fandom. However, recent changes in the professionalisation and commercialisation of sport have resulted in the creation of new spaces for fan experiences. In this paper, we examine one of these created spaces, the fan zone. Through a case study on match going fans of Everton Football Club we explore how this new space sits alongside traditional pre-match gathering places such as the 'pub' and examine the gendered organisation of these spaces. Drawing on Bale's concept of boundaries within sports fan communities we show that traditional venues for pre-match activities enhance, maintain and legitimise masculine boundaries within sports fandom. We argue that fan zones provide an alternative match-day atmosphere and experience that is centred on a family friendly or at least family inclusive culture.
\end{abstract}

\section{Keywords}

Sports Stadiums, Football, Space, Ethnography, Gender, Fandom, Sportscape

Football stadiums have been described as emblems of local identity that are inherently influenced by norms of masculinity (Giulianotti \& Armstrong, 2002 see also Armstrong, 1998; Armstrong \& Harris, 1991). As a site, they have long been cast as masculine spaces (Bradbury, 2011; Hughson, 1999; Rubin, 2009; Wenner, 1998), and spaces for the construction and maintenance of masculinity (King, 1997; Levant, 1997; Pearson, 2012; Pope, 2010). However, changes made to spaces in and around football stadiums have disrupted this masculine tradition. Clubs are increasingly marketing their brand as family friendly, or at the very least family inclusive (see Cashmore \& Cleland, 2012; Hughson \& Poulton, 2008; Tapp \& Clowes, 2000). The development of new sporting spaces that these fans engage with en route to a stadium then challenges the naturalised and taken-for-granted hyper-masculine discourse traditionally associated with match-day culture. The creation of official fan zones, we suggest, provides alternative experiences for some fans where prematch entertainment is used to engage and maintain fans' interest (and generate income) before they take their seats in the stadium (Gladden \& Milne 1999). However, these spaces 
1 remain on the periphery of football culture, which still promotes a conventional 'masculine space and image' (Pope, 2017: 171).

In this study we consider how these new spaces coexist within traditional masculine football cultures through physical and cultural gendered boundaries instituted by male and female fans alike. Through a qualitative case study of Everton Football Club (hereafter Everton), this paper explores two popular pre-match locations that highlight how the spatial dimension of the sport environment remains crucial to understanding match-day fan behaviour. In doing so we aim to show that the spatial and social environment of match-day influences and encourages various types of sports fan behaviour within particular locations through physical and cultural boundaries. The concept of boundaries describes the complex structures - physical, social, ideological which establish differences and commonalities between women and men, among women, and among men (Gerson \& Peiss, 1985). Applied to the sporting context, we consider how the symbolic and physical spaces within the matchday setting reaffirm localised, heteronormative and gendered boundaries that naturalise football as a 'male preserve' (Dunning, 1994). However, we also explore how the creation of new match-day spaces can challenge traditional forms of (hyper) masculinity and male gatekeeping within the sporting context.

\section{Conceptualising (Gendered) Boundaries in Sports Fandom}

This use of the concept of boundary within a sports fan community has been applied by Bale (1993a, 1993b, 1996, 2000, 2002a, 2002b), who highlighted that sport with its enclosures and rivalries is an important site for spatial analysis. Bale recognised that although sports fans may support the same team, a categorical and physical distance separated different groups of fans inside the stadium. The focus of boundary in his work remained predicated on social class, where fans from primarily the working classes were spatially segregated from other fans as the more socially and economically desirable groups of spectators were located in corporate boxes (Bale, 1993b). We broaden his perspective to account for the continuity, shifts, and strains in the construction of gendered boundaries in the contemporary football crowd. This focus builds on recent academic interest in how physical and social spaces can reflect gendered norms within society (Carr, 2017; Mowl \& Turner, 1995; Pavlidis, 2018; Van-Ingen, 2003; Waitt, 2008). Recently, an edited collection by Koch (2017) explored the issue of sport, space, and power and advocated the importance of advancing a critical geography of sport. Turcott (2018) suggested that the collection provided a much needed 21st 
1 century rendition of Bale's work. Written as a diverse set of case studies from a wide range of sports, the collection foregrounds gender and the role of sporting spaces in (re)producing gender hierarchies (Koch, 2017). Building on such work, this paper also extends Bale's work in response to socio-spatial and cultural changes to the match-day routines of football fans. 'New' spaces such as official fan zones remain largely absent in his work, but which we consider as inscribing an alternative experience to match-day that celebrates 'family friendly entertainment value' (Myrdahl, 2009: 294).

Scholars exploring the relationship between space and gender within a sporting context have built on Bale's (1993a, 1996, 2002b) concept of sportscape, which refers to the monocultural space within a city that is devoted to sporting practices. This includes the football stadium and also the immediate material surroundings that encompass the sports field/stadium (Bale, 1996). The sportscape is often the focus of intense power struggles over, for example, the building of stadiums and/or the temporary or permanent closing of public space for sporting events (John, 2015). In the modern context of football, the sportscape includes the stadium as well as 'spaces' such as public houses (pubs), take-away shops, and the streets that surround it that are frequented and transformed on match-day. Traditionally, it has been the local pub that has provided the setting for pre-match gatherings of fans which, as detailed by Collins and Vamplew (2000) has a long association with football. Fans (predominantly males) have gathered at pubs for many years (both pre and post-match) and these spaces have been described as 'an enduring site for fandom practice' (Dixon, 2014: 382). More recently, pubs have also become venues for watching 'live' sport on the television, particularly for those without access to sport on subscription television (Weed, 2006; 2007; 2008), further highlighting the importance of this space and the evolving nature of fandom.

However, the need for football clubs to improve aspects of safety following stadium tragedies such as the Hillsborough disaster and the Taylor report in the UK (Turner, 2014) has necessitated changes in the built environment of sportscape (Malcolm, Jones \& Waddington, 2000; Finnegan and Rookwood, 2008). Recent stadium developments have also been driven by commercial imperatives with a desire for venues to be used for a variety of business activities and even other sports (Church \& Penny, 2013; Kennedy \& Kennedy, 2010). Weed (2006) has argued that this 'sanitising' of stadiums has resulted in a culture of 
1 a site, the pub is considered a public space where men can 'mobilize and exert forms of control' (Campbell, 2000: 564). Yet these developments are also shaping stadium spaces for fans to frequent. Subsequently, new spaces such as official fan zones are considered in this paper as legitimate sites of match-day engagement. It should be noted that Bale remains somewhat critical of changes to traditional football stadiums, charting how the earlier suburban ground is slowly being replaced by new multipurpose football stadiums, what he describes as the 'tradium' - a commercialised space centred on mass consumption (2002a: 135). He considers such landscapes to be 'inauthentic', warning that modern football stadiums may become synonymous with concrete bowls or bland forms of container architecture (Bale, 1993b: 128). However, we argue this criticism only applies when describing the atmosphere favoured by those whom follow the traditional match-day routines discussed earlier.

Whilst fan zones have received some scholarly attention (Brannagan \& Rookwood 2016; Klauser, 2012; Lauss \& Szigetvari, 2010; Schnitzer \& Stickdorn, 2012), the large majority of this work focuses on mega-events and international football competitions. Hagemann for example, investigated the UEFA European Football Championship in Zurich and describes fan zones as extensions of the carnival where 'the streets chosen as routes for visitors, referred to as 'Fan Miles' or 'Fan Boulevards', carefully stage-manage the walk through each downtown area to the fan zone' (2010: 725). Fan zones at English football stadiums, however, are tailored towards a family match-going crowd, where offerings appeal particularly to young children. In these spaces, fans often partake in activities that include football-related games for children, jumping castles and other inflatable obstacles, and 'meet and greets' with players prior to the match. Therefore, we define fan zone as bounded spaces external to the stadium that are set aside for family friendly fan engagement activities.

We suggest that as football has been institutionally organised with a focus on 'competition and hierarchy amongst men and the exclusion or domination of women' (Connell, 2005: 54), further consideration should be paid to the gendered nature of the football sportscape. More specifically, how masculinity is not only constituted through fan behaviour inside and around the stadium, but also how the spaces where these engagements take place actively encourage or discourage particular fandom performances. In English football, these behaviours have included violent and exaggeratedly aggressive practices in resistance to authority and the use of language that is often sexist or homophobic (Jones, 
1 2008). Jensen (1992:15) paints a colourful image of typical fan behaviour being 'drunken

2 destructiveness, a rampage of uncontrollable masculine passion that is unleashed in response to a sports victory or defeat'. Such behaviours have forced female fans to downplay their gender identities (Jones, 2008) for fear of being labelled as 'inauthentic' sports fans (Pope, 2014a). Sport is considered a crucial site for the demarcation of gender as it 'serves to reproduce males as the standard and hegemonic hyper/masculinity as the norm' (Mean, 2010: 144). Each of the spaces, traditional and new, explored in this article will be shown to have created boundaries that mark belonging and exclusion. This study contributes new insights into match-day experiences of sport fans and gender relations in society more widely, demonstrating that space is political and contestable. We contend that the dynamics of gender power relations exert control over who belongs in particular spaces as well as the nature of particular interactions that occur within these spaces,

\section{Method}

An interpretivist, qualitative case study method was adopted for this study. Case study research is a stand-alone method that involves an in-depth investigation of a phenomenon within its 'real-world' context. Multiple sources of evidence are used and the case study method is often seen as synonymous with qualitative research (Edwards \& Skinner 2009). In this instance, an ethnographic approach was adopted, utilising participant observation and qualitative interviews. Drawing on data generated for a study that focused on the match-day experiences and spatial location of Everton fans, this paper describes the process of travel to and subsequent engagement in spaces surrounding Everton's home stadium of Goodison Park (hereafter Goodison).

Participant observation has been used to study marginalised subcultures in sport, with a particular focus on dysfunctional fans and hooligans (Armstrong \& Harris, 1991; Giulianotti, 1999; Hughson, 1999;). Fieldwork data was collected over three Premier League football seasons. In total, 20 matches were observed at Goodison by the lead author. Each match generated approximately 4.5 hours of observation (including travel time), which totalled approximately 100 hours in the field. The field consisted of Goodison and various sites that fans favoured on match-day. In this way, observations extended to the streets leading up to Goodison, food and merchandise stalls, as well as the pubs and fan zones. Due to the confines of a research article, we have chosen to discuss observations of a typical pub on County Road and Everton's fan zone. The selected pub is a large white building that is a 
1 5-minute walk (0.2 mile) to Goodison. It has eaves painted in the blue of Everton's club 2 colours, with some black paint forming a perimeter at the bottom of the building. The bright and dominant colours of blue, white, and black, are associated with Everton and act as symbolic markers (Cohen, 1985) to reaffirm to local residence that this is a 'blue pub'.

Recording fieldwork notes would have been impossible to do whilst in the field and so the researcher wrote them after match-day observations, usually on the night of the match. A mobile phone was often used to write 'buzz words', or what Bernard (2006: 389) refers to as 'jotting notes' during observations. These in effect were short sentences or words that would later act as trigger material and assist in recalling events that had happened during the observations (AUTHOR A, 2016). The use of mobile devices by sports fans is now relatively common at sports matches, with many teams and stadiums offering free Wi-Fi and encouraging the use of mobile devices (Turner, 2014). Therefore, using devices to make initial observations and thoughts did not need to be furtive, and was seen as acceptable fan behaviour by those around the researcher. Using a mobile device with in-built photographic capabilities had the added benefit of allowing events to be recorded 'in multiple modalities' (Yin, 2011: 161).

This research also involved 25 semi-structured interviews with participants aged between 20 and 70. Of those interviewed, fifteen were male and ten were female. One participant had a physical disability, and two of the participants were mothers to young children. The participants were all season ticket holders (club members), apart from two who attend Goodison regularly with friends. In this way, the research subscribed to 'purposeful sampling' where suitable participants were sought out to discover, understand, and gain insight about a particular phenomenon (Merriam, 1998). As the research became more refined in its focus, the maximum variation purposeful sampling technique was applied to refine and guide the types of participants that were recruited.

What became apparent was the diversity in the football crowd with notable differences in fans that were not entirely influenced by just gender and age. As a result of this observation, the researchers shifted to recruiting fans, such as family fans (identified as mixed-gender groups of adults and children), whose match-day experiences have often been overlooked (AUTHOR A, 2018 in press). This adaptability enabled the research to expand on the typical framework of sports fandom that homogenises the sports crowd as a single unit. The aim of utilising this approach was to build on such work, by examining a wider spectrum 
of fans on match-day, rather than focusing primarily on one fan type. Whilst this approach has limitations, including lacking Geertzian's (1973) 'thick description' of one subcultural group that is favoured by many football scholars, in many ways its breadth, as will be explained later in this paper, gave a voice to fans that have typically been silent in academic literature.

\section{County Road: Beer and Banter}

I met Angus's wife tonight at the pub. I sat with her and their two children before the match at the tables near the window. Angus didn't really hang around, but left me there while he spoke to some of his friends near the bar. I can't remember her name, but we spoke about her son playing football this weekend. I asked why she comes to the pub but does not attend the matches. She remarked that it was 'his' [referring to Angus] domain. She noted that she enjoyed coming to the pub and hanging out with everyone but really had no interest in football, and was actually, if anything, because of her family was a Liverpool fan. But I was told in a joking matter to not remind Angus of this fact.

(Fieldwork Note: 1/11/2014 vs. Norwich City)

County Road sits just behind Goodison and is an iconic and revered space for Everton fans. The street is lined with pubs and a variety of takeaway shops, grocery stores and gambling/betting agencies. Observations on County Road revealed fans that spent time here pre / post-match were very familiar with the site. No one appeared lost, no one asked for directions, and no fans were observed taking photos of the landscape. Perhaps this is not that surprising considering it is not a particularly attractive streetscape. In fact, some fans actively avoided the street due to its unappealing nature or because it was considered to be 'too busy' and/or 'full of young drunk people'. As Cathy notes,

If my plan was to drive in, well there's nowhere to usually go in Walton ${ }^{1}$, you know. Whereas in town, you know, you can go to the coffee shop or whatever...but you know, let's face it, Walton's not a gentrified area and I think, well I'm gentrified now (laughs).

(Interview: Cathy, 50-60).

${ }^{1}$ Walton is the area where Goodison and County Road are located. 

more than, important than the match itself. These fans were overwhelmingly young males and tended to be heavily involved in activities such as singing and chanting fan songs in and around the pubs (and at games). As a group, they appeared to embody a hedonistic lifestyle centred on mass consumption of alcohol (prior to entering Goodison). It is pubs that assume the greatest importance for many Everton fans where socialised drinking served to legitimate and reproduce masculine bonding as a ritual (Rowe \& Gilmore, 2009). As Chris explained when describing his early experiences of going to the match,

And then when I was old enough to drink or almost old enough to drink...a drink in one of the locals before going in [to Goodison].

The relationship between hyper-masculine, boisterous fan types and pubs has been well documented in literature, with Weed describing the relationship between football, alcohol and male bonding as "the holy trinity" (2007: 400). Armstrong notes that pubs form the meeting spot before the match, and 'the ones favoured by fans were within walking distance of the football stadium' (1998: 195). Similarly, Pearson described pubs as 'factories' where these fans would work together to create songs and build social solidarity before the match (2012: 66). Bale's work on sportscape highlights that locations such as pubs work to evoke the different senses - mainly sight but also smell, sound and nostalgia which contribute to a positive sense of place for a sports fan (2002b: 19). Dixon further noted how pubs are also a site for masculine bonding in relation to football that he contends is 'an acceptable leisure pursuit for men that is passed down by football fans from one generation to the next' (2014: 388). The findings of this research suggest something different. Pubs on County Road were not just for hyper-masculine fans and men generally, but are rather a melting pot of a variety of fan types on match-day.

Historically, pubs are conceived as a space for male bonding on match-day (Brown, 2010; Wenner \& Jackson, 2009). Leyshon (2008) describes how they are a highly territorialised place colonised mainly by different groups of men, resulting in women and the spaces that they occupy being in marginal areas such as the corners, along the sides, and in beer gardens. Within this pub there was an organised structure in relation to where particular fans were situated. For example, family fans sat together at the front, with the standing area 
1 immediately around the bar dominated by mostly male fans. Female family fans were observed to be more likely to take on primary childcare responsibilities in the pub setting, reflecting how gendered norms pertaining to motherhood and parenting remain in match-day settings. Male family fans were observed to be more fluid, moving between sitting/standing at the tables and standing around the bar located in the centre of the pub. They were not bound by the space and had the ability to move freely between sections. This fluidity of movement between social groups and locations was not afforded to female family fans during observations. In this way, gendered spaces do not just simply exist, but are produced through the expectations of gender stereotypes inscribed into space. As females had the primary responsibility for caring for children they are confined to this peripheral space and become marginalised. Put simply, the front section of the pub was designated as the family space and therefore this is where females were 'expected' to sit. As a result, family fans were located in a peripheral position of the main bar and overall space of the room, seated at the front tables. From observations, female family fans used this space to socialise; football was secondary or sometimes completely absent from discussions.

Female family fans often sat with others at the front of this pub where groups of young children would play, at times unsupervised. As such the front section of the venue is an example of a feminine community of practice, where children were taught localised masculine and feminine practices through the constant production, reproduction, and negotiation of what it is (or what it means) to be a male or female in this environment (Paechter, 2003). As the vignette at the start of this section reflects, Angus took his young son into the middle standing section where he was encouraged to interact with other older, 'traditional' male fans. This group were distinguished by the longevity of their support and their in-depth sport knowledge associated with Everton. His daughter (of similar age) on the other hand, remained seated with his wife and the (female) researcher at the table. Therefore, his son was introduced to the masculine and engaged space of football and being a football fan, while his daughter remained on the fringes by being seated with her mother and the other family fans in this front section of the pub.

I think it's the culture of the game. It's how it happens in England. It's a case of the way families are perceived. It's like the boys go with their Dad's to the game and the girls go shopping with their Mum but you know on the day of the game. That's how it has always been sort of thing but I think it's starting to 
break, you know, you can see a difference but it's slow in coming. But I think that's the only reason why it's just a habit, nothing more.

(Interview, Alison 30-40)

Paechter (2007) argues that relations within and between localised masculine and feminine communities of practice underpin strict gender relations. As the above quote reflects, this resonates with how fans perceive the gendered landscape of football culture in England. This assumption is further supported when juxtaposing the family section of the bar with the area behind it. The section behind the group of tables that family fans occupied was a standing area (there were no seats and tables) where mostly male fans formed a tight circumference around the bar that was at times five people deep. Although some females were present in this section of the pub, fans here embodied hyper-masculine displays regardless of their gender (Butler, 1988, 1990).

I overheard a male fan decline a beer, with his friend calling him 'soft' and 'weak' and suggesting that he was 'unworthy' of being an Everton fan.

(Fieldwork Note: 1/2/2014 vs. Aston Villa)

This accusation aligns with working class masculinities discussed above, where through the public performance of drinking alcohol, dominant understandings of legitimate masculine behaviour are reinforced and defended (Campbell, 2000; Connell, 2005). This type of fan behaviour is described as a masculine celebration of community, displaying strong forms of local identification and an equally strong tendency to denigrate other (opposing) suburban communities by means of songs and chanting (Bale, 2002b: 18). It was observed that female fans who stood in this section were always in a group, and the group's composition was mostly men. Wenner (2009: 214) describes this as one of the core features that makes the space of a pub a masculine domain or a 'symbolic site where women are excluded, marginalised, or required to be accompanied by men'. Significantly, even when these female fans were not physically marginalised and restricted to the front section, they are symbolically marginalised as will be detailed below.

The power dynamics of sports knowledge, as Messner (1988) has suggested, reproduces hegemonic masculinity of which gender difference is shown to be a key part. For example, in interactions in spaces such as pubs, females are more likely to be 'interrupted and contributions undermined by men' (West and Zimmerman 1977 in West, 1996: 359). On multiple occasions the explanation of simple rules to some female fans (including the 
researcher) was imbued with unnecessary jargon. Interactions such as these positions male fans in a privileged, powerful position in the Everton community. This type of 'sport talk', further reinforced boundaries that worked to exclude females from the culture of football. These boundaries translate informally into influence and authority that further strengthened the masculine boundary that exists in this space (Cohen, 1985). However, this is not to say that some female fans were not knowledgeable or capable of 'sports talk'. As Jones (2008) found, some female fans in this setting adopted traditional performances of masculinity, such as excessive drinking and criticising female fans who embodied femininity. On occasion, these female fans would call their presence on match day 'a waste of a ticket'.

Well, I go as a woman, but I feel I probably behave like a man...I enjoy talking football at the level that men talk about football...I am the only girl and I like that. Because generally, I suppose I think the girls who go to Everton are scouse girls ${ }^{2}$ and I don't identify with them. You see them, women tossing their hair around and in their high heels and I don't ... that isn't me. So I think you're here not doing women who understand football any credit

\section{(Interview, Samantha, 30-40)}

In observations, these 'Scouse girl' fans and their male peers would usually arrive late to the match, a practice which remains synonymous with post-all-seater stadium culture. They would seek to stay as long as possible in pubs where they were able to consume alcohol in a less regulated environment compared to the stadium (Pearson, 2012). The behaviour of these fans on the walk up to Goodison reflected a socio-spatial transition from an unregulated environment (in so far as Everton was not affiliated with the pubs) to the stadium environment. This transition was marked by distinctive changes in behaviour, where fans were observed to conform to what they perceived to be strict regulations around intoxication within and around the stadium. As the following fieldwork note illustrates, this was mostly achieved by pretending to be sober before entering into the stadium.

On the walk up tonight, one of the lads remarks- 'oi, sober face on lad, you've got to just get through the gates'.

\section{(Fieldwork Note: 1/02/2014 vs. Aston Villa)}

However, prior to entering into the stadium, most fans would bypass or transition through the carpark that surrounds Goodison. This location hosts the official fan zone that is

\footnotetext{
2 'Scouse Girls' is a term commonly used to describe women and girls who are born in Liverpool that adopt hyper femininity. 
1 organised and run by Everton and Everton in the Community (charity affiliated with the 2 football club). Although Bale does not discuss this type of landscape in his work, we consider the fan zone as a space that prescribes and advances his conceptualisation of the sportscape.

\section{A Different Kind of Atmosphere: The fan zone of Goodison}

Stacey tells me today that you just can't be drunk in the fan bit because there are children everywhere. She described and then actually took me to the entrance of the fan zone, near the van, and points to the Main Stand entrance and says that drunk people walk past all the time to get into Goodison, but she had not seen anyone drunk in there [the fan zone] before. She then commented on how she hated that people smoked inside the confined area of the fan zone, saying that she didn't think it was good and that smokers should move outside.

(Fieldwork Note: 6/1/2015 vs. West Ham United)

The Everton fan zone on match-day is a small partitioned off space inside Goodison's car park. During the week this space functions purely as a car park, but on match-day it is transformed into a location where fans can partake in a variety of activities, games, and purchase official Everton products from merchandise vans. Framing the fan zone are food stalls, where fast food offerings similar to that inside of the stadium such as burgers and fish and chips are available prior to the match. It was observed to be mainly occupied by male and female family fans that transition through this space en route to Goodison, usually interacting with the zone for one to two hours before kick-off. Given this space is primarily created for families and children, inclusion remained predicated on women and girls performing a particular type of femininity, mostly in the capacity of a nurturing feminine role (AUTHOR A, 2016).

Although there were some male fans present in this section, compared to the observations made in the pub, there was a stronger female presence. On one hand, official fan zones can be seen as breaking down the traditional gender-bound divisions of weekend time, and replacing the masculine pre-match ritual of drinking in local pubs before the match with more family orientated fan engagement. On the other, this introduction ensures that the existing culture of football is upheld with family fans separated from the traditional locales of masculine football culture and spaces interacted with on match-day.

Twenty-first Century football has been accused of lacking atmosphere, attributed to topographical changes in football stadiums and the commercialisation of sport (Charleston, 
1 2008; Nash, 200). However, that line of argument can only be applied when describing the atmosphere favoured by the hyper-masculine fans discussed in the previous section. Although Bale has discussed at length the modernisation of sports stadiums, particularly those developed and designed with improved satisfaction and performance, he argues that the overall sports experience is diminished in such environments (Bale, 2002b: 159). This paper advances these discussions, by exploring how the fan zone sportscape provides a 'new' atmosphere.

The atmosphere generated in the fan zone is not built on history, memory or tradition, but rather developed from fans engaging with prearranged activities and entertainment, commercial products, and technology-based artefacts and practices. For example, fans were encouraged to take photos of their children inside of the fan zone, either doing activities or having photos with invited guests. They are then invited to tweet the photos to Everton through the hashtag \#EFCfanzone, with a chance that the photo will be projected onto the big screen during the match. This type of fan engagement has recently received attention from scholars, mostly in light of the advent of digital technologies which significantly increase the ability of sports fans to openly express their identity as a fan on match-day. Although Redhead (2015) describes Twitter being used by football fans to vent frustrations, it can also be useful for clubs attempting to appeal and reach out to family fans.

Well, I think they seem to be doing a lot more of the fan stuff now. They seem to be doing a lot more to invite families and get the kids going. They didn't really have anything like that when I was a kid, well not that I remember anyway. I guess they do a lot more novelty days. They have like vintage day where they have old shirts, I think the sort of thing, like that makes football seem a lot friendlier.

\section{(Interview: Will, 20-30)}

I also suspect that the watching population is ageing in this country, and you don't see as many young, you know teenagers going anymore. The majority of people going to the match would be maybe my ages, mid 50's and you wonder where that is going to lead. You wonder whether the support is just going to tail away in the end. That's why they've got the fan zone I think, got to keep the young kids happy and into it, you know.

(Interview: Paul, 40-50)

However, whilst the demographic of supporters has changed (Cleland, 2010) the attitudes toward these new types of match-day routines, particularly the use of digital 
1 technology inside of the stadium are less well understood (Tapp and Clowes, 2000). As the quotes above reflect, Everton fans are conscious of a perceived change to the demographic of the football crowd, but spoke generally in favour of these changes in making football more inclusive. However, Pearson (2012) notes that for some hyper-masculine fans the act of taking photos and videos through mobile phone technology during matches was considered the type of activity a 'tourist' or non-authentic fan would engage in. According to some traditional fans, authentic fans 'should be merely supporting the team' and not engaging in that type of activity (Pearson, 2012: 179). As a consequence, official fan zones remain on the 'other side of the boundary' (Cohen, 1985) of what has been considered traditional football culture and hence peripheral to the game's masculine ethos (Williams, 2006). Exploring how behaviour in and around the official fan zone was policed by the club and also the matchgoing crowd who frequent this space illustrates how boundaries were created and reinforced to ensure this space remains safe for families and young children.

Unlike the spatial arrangements of fans inside the pub, male family fans were observed to stand in a small section at the rear of the fan zone that serves alcohol. Although this also involved them then being physically separated from female family fans and children, they were now marginalised away from the focal point of the space - the main stage. Female family fans were again observed to be more engaged with their children and involved in the activities offered in the fan zone. Although traditional match-day food and alcohol consumption is encouraged in this zone, all fans are under much tighter regulations and surveillance than those in pubs not only by the club's official security, but also by others fans within this space. In this way, family fans are not perceived as passive or delicate objects that need protecting. This finding stands in contrast to how female fans particularly have been perceived within the sporting context, especially within sport crowds (Pope, 2014a). Rather, it was observed that female family fans were the ones doing the protecting and gatekeeping, especially when it came to their children - a practice of self-policing that is becoming more common amongst fans (Millward, 2008). The female family fans that took part in this study deemed intoxication, smoking, and other supposed 'anti-social' activities as not appropriate behaviour within this part of the sportscape, as exemplified in Stacey's comments at the beginning of this section.

The fan zone is a space that is dominated by family fans that were observed to maintain (and at times defend) the boundary between themselves and other fan groups. The 
symbolic expression and affirmation of this boundary heightens awareness of and sensitivity to fans within this space (Cohen, 1985). Members of other fan groups were observed to respect this boundary, by actively avoiding it to not cause a disruption to its 'social script' (Goffman, 1959). In the context of this study, this moral standard and reference group refers to family fans and the creation of a boundary between their behaviour, or what they deem to be appropriate match-day behaviour, and the boisterous, alcohol-fuelled behaviour of other fans that was discussed above. By keeping this behaviour outside of the official fan zone, the moral standard of the space is upheld. We are not postulating that family fans are inherently critical of hyper-masculine fan behaviour on match-day, but rather they create an alternative form of match-day atmosphere that does not rely on traditional (masculine) practices and performances of fandom.

\section{Conclusion}

This article has explored the spatial configuration of the match-day routine for Everton fans, and positioned this discussion within the broader framework of sportscape. It considered how traditional practices of a match-day still remain popular and attractive for Everton fans, whilst also discussing the creation of new spaces that fans can engage with before they enter the stadium. We suggest that the variety of fan types that locate themselves within the sportscape allows the meanings and significance tied to the match-day routine to shift, adapt and change with the currents of social, cultural and commercial influences. Whilst football remains in many ways a masculine 'preserve', we discussed how clubs have made a stronger attempt to encourage a more diverse fanbase, namely that of family fans. However, for both male and female fans inclusion into the sportscape was shown to have limits. Instituted through social and cultural boundaries, this inclusion remains based on gendered norms that, depending on the location, privileges traditional versions of either masculinity or femininity.

The various spaces fans chose to frequent on game day greatly contributed to the behaviours they exhibited. Match-day became a way for fans to distinguish themselves as members of a particular fan type within the Everton fan community. As such, the areas surrounding the stadium were shown to enhance, maintain and legitimise particular sports fan behaviours, where within particular spaces the idealised fan norms for the group were embodied and realised. Spaces such as County Road remained a part of the sportscape that encased an interlocking web of localised ideologies and traditional masculinity. The fans observed in this space typically were drawn to it with an expectation and understanding of the 
1 cultural traditions and carnival atmosphere it celebrates. The gendered spatial boundaries 2 within the pub ultimately result in both the physical and symbolic marginalisation of all 3 females. Even when they are 'permitted' into the masculine spaces, females continue to 4 be disempowered as they are 'forced' to adopt tenets of orthodox masculinity or are 5 devalued through the use of male-privileging practices such as 'sport talk'.

6 7

The fan zone, however, created a bridge for some fans between traditional (masculine) fan practices and family or community-oriented culture. Family fans, particularly, were able to create a distinction or boundary between themselves and the undesirable elements of hyper-masculine fan culture. In this way, they created an alternative match-day atmosphere and experience that remains centred on a family friendly or at least family inclusive culture. In doing so, family fans create social solidarity amongst its members and carve out the space where their performance and embodiment of fandom is not marginalised or ridiculed, but rather protected and upheld by the other members of the Everton fan community. Unlike the pre-match activities that take place on County Road, the fan zone celebrates new types of fan engagements and commercial artefacts. Although this type of engagement can be seen as problematic in literature, it is set to increase in the contemporary game, due to the large amount of financial investment football clubs are putting into developing fan zones. Whether or not the fan zone will become cemented in the match-day routine for football fans remains uncertain, as does the vitality of this particular fan zone if Everton were ever to be relocated to another stadium.

Perhaps more importantly it reveals how the social and physical landscape of space remains bounded in gendered norms which influences behaviour and sets expectations. With the creation of new spaces, those who inhabit them will develop their own norms and boundaries which can marginalise traditional practices and create alternative inclusive environments. While this explanation appears to binarise these two sites as (traditional) masculine and feminine spaces the situation is much more fluid. As with any spaces, these locations are in a state of flux due to the complex human relations that take place within them. They become sites for resisting, overcoming and negotiating power.

To conclude, this paper illuminates the largely overlooked socio-spatial element inherent to sports fandom. In doing so, we have also addressed a gap in our understanding of spatiality - namely the geography of sport (Molw \& Towner, 1995; Pavlidis, 2018). Hopefully this paper will inspire other researcher to focus on the geography of sport in urban settings. 


\section{Works Cited}

4

5

6

7

8

Armstrong, G. (1998). Football Hooligans: Knowing the Score. Oxford: Berg.

Armstrong, G. \& Harris, R. (1991). Football hooligans: theory and evidence. The Sociological Review, 39(3), 427-458.

Bale, J. (1993a). Sport, space, and the city. London: Routledge.

Bale, J. (1993b). The Spatial Development of the Modern Stadium. International Review for the Sociology of Sport, 28 (2-3), 121-133.

Bale, J. (1996). Space, place and body culture: Yi-Fu Tuan and a geography of sport. Geografiska Annaler, 78(3), 163-171.

Bale, J. (2000). The changing face of football: stadiums and communities. Soccer and Society, 1(1), 91-101.

Bale, J. (2002a). Cartographic fetishism to geographical humanism: Some central features of a geography of sports. Innovation, The European Journal of Social Science Research, 5(4), 71-88.

Bale, J. (2002b). Sports Geography ( $2^{\text {nd }}$ ed.). London: Routledge

Bernard, H. (2006). Research methods in anthropology: Qualitative and quantitative approaches. Lanham: Altamira Press.

Bradbury, S. (2011). From racial exclusions to new inclusions: Black and minority ethnic participation in football clubs in the East Midlands of England. International Review for the Sociology of Sport, 46(1), 23-44.

Brannagan, P. \& Rookwood, J. (2016). Sports mega-events, soft power and soft disempowerment: international supporters' perspectives on Qatar's acquisition of the 2022 FIFA World Cup finals. International Journal of Sport Policy and Politics, 8(2), 173-188.

Brown, A. (2010). Come home: The stadium, locality and community at FC United of Manchester. In S. Frank \& S. Steets (Eds.) Stadium worlds: Football, Space and the Built Environment (pp. 163-179). London: Routledge.

Butler, J. (1988). Performative acts and gender constitution: An essay in phenomenology and feminist theory. Theatre Journal, 40(4), 519- 531.

Butler, J. (1990). Gender trouble. New York: Routledge.

Campbell, H. (2000). The Glass Phallus: Pub(lic) Masculinity and Drinking in Rural New Zealand. Rural Sociology, 65(4), 562-581.

Carr, J. (2017). Skateboarding in Dude Space: The Roles of Space and Sport in Constructing Gender Among Adult Skateboarders. Sociology of Sport Journal, 34(1), 25-34. 
1 Cashmore, E. \& Cleland, J. (2012). Fans, homophobia and masculinities in association

2 football: evidence of a more inclusive environment. The British Journal of Sociology, 63(20),

$3 \quad 370-387$.

4 Cleland, J. (2010). From passive to active: the changing relationship between supporters and

Charleston, S. (2008). Determinants of home atmosphere in English football: A committed 8 supporter perspective. Journal of Sport Behaviour, 31(4), 312-328.

9 Cohen, A. (1985). Symbolic Construction of the Community. London: Routledge.

Collins, T. \& Vamplew, W. (2000). The pub, the drinks trade and the early years of modern football. The Sports Historian, 1(20), 1-17.

Connell, R. (2005). Hegemonic masculinity: Rethinking the concept. Gender and Society, $19(6), 829-859$.

Crawford, G. (2004). Consuming sport: Fans, sport and culture. London: Routledge.

Crolley, L. \& Long, C. (2001) 'Sitting Pretty? Women and Football in Liverpool'. In J. Williams (Eds.), Passing Rhythms: Liverpool FC and the Transformation of Football (pp. 195-214) Oxford: Berg.

Dixon, K. (2014). The football fan and the pub: An enduring relationship. International Review for the Sociology of Sport, 49(3-4), 382-399.

Dunning, E. (1994). Sport as a Male Preserve: Notes on the Social Sources of Masculine Identity and its Transformations. In S. Birrell \& C. Cole (Eds.), Women, Sport and Culture (pp. 163-179). Leeds: Human Kinetics.

Edwards, A. \& Skinner, J. (2009). Qualitative Research In Sport Management, London: Butterworth-Heinemann.

Finnegan, P. \& Rookwood, J. (2008) Taking a stand? Examining fan culture and the proposed re-introduction of allocated standing areas in British football stadia. Journal of Qualitative Research in Sport Studies 2(1), 99-114.

Gerson, J. \& Peiss, K. (1985). Boundaries, negotiation, consciousness: reconceptualizing gender relations. Social Problems 32, 317-331.

Geertz, C. (1973). "Thick description": The interpretation of cultures. New York: Basic Books.

33 Giulianotti, R. (1999). Hooligans and carnival fans: Scottish football supporter cultures. In G. Macmillian.

36 Giulianotti, R. \& Armstrong, G. (2002). Avenues of contestation: Football hooligans running 
1 Gladden, J. \& Milne, G. (1999), Examining The Importance of Brand Equity in Professional 2 sport, Sport Marketing Quarterly, 8(1), 21-29.

3 Glass, M. \& Rose-Redwood, R. (2014), "Finding New Spaces for Performativity and 4 Politics," in M. Glass and R. Rose-Redwood (eds.), Performativity, Politics, and the 5 Production of Social Space (pp. 253-263). New York: Routledge.

6 Goffman, E. (1959). The presentation of self in everyday life. New York: Anchor Books.

7 Hagemann, A. (2010). From the stadium to the fan zone: host cities in a state of emergency.

8 Soccer \& Society, 11(6), 723-736.

9 Hughson, J. (1999). A tale of two tribes: Expressive fandom in Australian soccer's A-league. 10 Culture, Sport, Society, 2(3), 10-30.

11 Hughson, J. \& Poulton, E. (2008). 'This is England': sanitized fandom and the national 12 soccer team. Soccer \& Society, 9(4), 509-519.

Jensen, J. (1992). "Fandom as Pathology: The Consequences of Characterization" in L. Lewis (ed), The Adoring Audience: Fan Culture and Popular Media (pp. 9-29). London: Routledge.

John, A. (2015). Sports City: A critical analysis of Melbourne's sportscape. PhD thesis, Victoria University.

Jones, K. (2008). Female fandom: Identity, sexism, and men's professional football in England. Sociology of Sport Journal, 25(1), 516-537.

King, A. (1997). The lads: Masculinity and the new consumption of football. Sociology, 31(2): 329-346.

Klauser, F. (2012). Interpretative flexibility of the event-city: Security, branding and urban entrepreneurialism at the European Football Championships 2008. International Journal of Urban and Regional Research, 36(5), 1039-1052

Koche, N. (2017). Critical Geographies of Sport: Space, Power and Sport in Global Perspective. Oxon: Routledge.

Lauss, G. \& Szigetvari, A. (2010). Governing by fun: EURO 2008 and the appealing power of fan zones. Soccer \& Society, 11(6), 737-747.

Levant, R. (1997). The Masculinity Crisis. The Journal of Men's Studies, 5, 221-232.

Leyshon, M. (2008). We're stuck in the corner: Young women, embodiment and drinking in the countryside. Drugs: education, prevention and policy, 15(3), 267-289.

Lenskyj, H. (1995). Sport and the Threat to Gender Boundaries. Sporting Traditions, 12(1), 47-60.

Malcom, D. Jones, I., \& Waddington, I. (2000). The people's games? Football spectatorship and demographic change. Soccer and Society, 1(1), 129-143. 
and Gender: Promotional Culture and Contemporary Social Life (pp. 143-161). New York: Peter Lang.

Merriam, S. (1998). Qualitative Research and Case Study Applications in Education. San Francisco: Jossey-Bass.

Messner, M. (1988). Sport and Male Domination: The Female Athlete as Contested Ideological Terrain. Sociology of Sport Journal 5, 197-211.

Millward, P. (2008). The Rebirth of the Football Fanzine: Using E-zines as Data Source. Journal of Sport and Social Issues, 32(3), 299-310.

Mowl, G. \& Towner, J. (1995). Women, gender, leisure and place: towards a more 'humanistic' geography of women's leisure. Leisure Studies, 14(2), 102-116

Myrdahl, M. (2009). "Family-Friendly" without the Double Entendre: A Spatial Analysis of Normative Game Spaces and Lesbian Fans. Journal of Lesbian Studies 13(3), 291-305.

Nash, R. (2001). English football fan groups in the 1990s: Class, representation and fan Power. Soccer \& Society, 2(1), 39-58.

Paechter, C. (2003). Masculinities and femininities as communities of practice. Women's Studies International Forum, 26(1), 69-77.

Paechter, C. (2007). Being Boys, Being Girls: Learning masculinities and femininities. Berkshire: Open University Press.

Pearson, G. (2012). An Ethnography of English football fans: Cans, cops and carnivals. Manchester: Manchester University Press.

Pavlidis, A. (2018). Making "space" for women and girls in sport: an agenda for Australian geography. Geographical Research, 56(4), 343-352.

Pope, S. (2010). Female fandom in an English 'sports city': A sociological study of female spectating and consumption around sport. PhD Thesis. Leicester: University of Leicester.

Pope, S. (2014a). 'There Are Some Daft People Out There': exploring female sport and media fandoms. Sport in Society, 17(2), 254-269.

Pope, S. (2014b). Female Football Fans and Gender Performance. In Anderson, E. \& Hargreaves, J. Routledge Handbook of Sport, Gender and Sexuality (245-253), London Routledge.

Pope, S. (2017). The Feminization of Sports Fandom: A Sociological Study. London: Routledge.

Redhead, S. (2015). Football and Accelerated Culture: This Modern Sporting Life. London: Routledge

Rowe, D. \& Gilmour, C. (2009). Lubrication and Domination : Beer, Sport, Masculinity, and the Australian Gender Order. In L. A. Wenner \& S. J. Jackson (Eds.), Sport, beer, and gender: promotional culture and contemporary social life (pp. 203-221). New York: Peter Lang. 
1 Rubin, M. (2009). The offside rule: Women's bodies in masculine spaces. In U. Pillay, R.

2 Tomlinson \& O. Bass (Eds.), Development and dreams: The urban legacy of the 2010

3 Football World Cup (pp. 266-288). Cape Town: HSRC Press.

4 Schnitzer, M. \& Stickdorn, M. (2012). Key success factors for fan zones (public viewings) 5 covering mega sport events - the case of UEFA EURO 2008TM in Austria. European 6 Journal of Tourism Research 5(1), 19-37.

7 Tapp, A. \& Clowes, J. (2000). From 'carefree casuals' to 'professional wanderers': 8 Segmentation possibilities for football supporters. European Journal of Marketing, 36(119 12), 1248- 1269.

10 Toffoletti, K. \& Mewett, P. (2012). Introduction. In K. Toffoletti \& P. Mewett (Eds.). Sport and its Female Fans (pp.1-12). New York: Routledge.

12 Turcott, R. (2018). Book Review: Critical Geographies of Sport. International Review for the 13 Sociology of Sport, 53(4), 512-514

Turner, M. (2014). Modern English football fandom and hyperreal, 'safe', 'all seater' stadia: examining the contemporary football stage. Soccer and Society, 18(1), 121-131.

Van-Ingen, C. (2003). Geographies of gender, sexuality and race: Reframing the focus on space in sociology of sport. International Review for the Sociology of Sport, 38(2), 201-216.

Waitt, G. (2008) 'Killing waves': surfing, space and gender, Social \& Cultural Geography, 9(1), 75-94.

Weed, M. (2006). The story of an ethnography: The experience of watching the 2002 World 21 Cup in the pub. Soccer \& Society, 7(1), 76-95.

Weed, M. (2007). The pub as a virtual football fandom venue: An alternative to 'being there'?. Soccer \& Society, 8(2-3), 399-414.

Weed, M. (2008). Exploring the sport spectator experience: Virtual football spectatorship in the pub, Soccer \& Society, 9(2), 189-197.

Wenner, L. (1998). In search of the sports bar: Masculinity, alcohol, sports and the mediation of public space. In G. Rail (Ed.), Sport and Postmodern Times (pp. 301-332). New York: State University of New York Press.

Wenner, L. \& Jackson, S. (2009). Sport, Beer, and Gender in Promotional Cultire: On the Dynamics of a Holy Trinity. In L. Wenner \& S. Jackson (Eds.), Sport, Beer, and Gender: Promotional Culture and Contemporary Social Life (pp. 1-34). New York: Peter Lang 32 Publishing.

West, C. (1996). Goffman in Feminist Perspective. Sociological Perspectives, 39, 353-369.

Williams, J. (2006). Protect Me from What I Want: Football Fandom, Celebrity Cultures and 'New' Football in England. Soccer and Society, 7(1), 96-144. 
